\title{
The Use of Fungal Endophyte Penicillium citrinum on Tree Seedling: Applicability and Limitation
}

\author{
Safinah Surya Hakim ${ }^{1 *}$ and Tri W. Yuwati ${ }^{1}$ \\ ${ }^{1}$ Banjarbaru Environment and Forestry Research Development Institute, Banjarbaru, 70721. Indonesia
}

\begin{abstract}
Penicillium citrinum is an endophyte fungus isolated from plant tissues that live in tropical peatland. Various study reveals that endophytic fungi give advantages to plant health. Since 2015, series of experiments were conducted to investigate the capability of $P$. citrinum P3.10 as biofertilizer of plant tree in nursery stage which are: pathogenicity test, in vitro assay, direct application to seeds, dosage test, and fertilizer formulation. This paper presents a review from our research of $P$. citrinum isolate P3.10 from the isolation stage to the biofertilizer product formulation. Resear ch results showed that the application of endophytic fungi to seedlings gave positive responses. However, during the research process there were also obstacles in the application of endophytic fungi to plants, which are: (a) difficulties in application due to the varied response, (b) formulation, (c) storage, (d) isolate viability, and (d) fungal isolate maintenance. Risk management was needed during biofertilizer production. Hence, the utilization of biofertilizer made from endophyte fungi is applicable and can be used not only on an experimental scale but also on a larger scale.
\end{abstract}

\section{Introduction}

Naturally, plants have certain relationships with endophytes. It is reported that $90 \%$ of the plant do symbiosis with microbes, including endophyte fungi. Unlike mycorrhiza; which has specialized structures within its plant-fungus interaction such as arbuscules, Hartig net, vesicles; plant-endophyte interaction is deficient in specialized structures [1]. Nevertheless, plant-endophyte relationship according to many studies have significant benefits for the plant as follow: (a) Enhance plant growth [2-6], (b) Source of secondary metabolites that can be a benefit for plant and pharmaceutical needs [7-10], and (c) Induce plant resistance to pest and disease [10-12].

Many fungi identified as endophytic fungi, including Penicillium citrinum. During this research, $P$. citrinum show the ability to improve the growth of the plant [13]. P. citrinum produced hormone Indole Acetic Acid (IAA), extracellu lar en zy mes, and auxin which can increase the growth of the inoculated plants [14]. Besides, endophytic fungi Penicillium sp. was indicated able to increase plant growth by increasing plant nutrient absorption [15].

To gain information on the biology and function of endophytic fungi in peat swamp forest, Banjarbaru Forestry Research and Development Institute has conducted a multi-year-research focusing on endophyte bioprospection. The research main purpose was bioprospecting microbe in peatland, particularly mycorrhizal and endophytic fungi. At the early stage of the research in 2015, exploration, isolation, and screening were carried out to identify endophytic fungi that could potentially increase plant growth. In the second year (2016), research activities were done to obtain information on the effectiveness of endophytic fungi on the plant through inoculation. At the next stage (2017), the research activities aimed to find out the best inoculation techniques and dosages for microbial applications in plants. In the last year (2018), the formulation was done to investigate the effective carrier for endophytic fungi-based biological fertilizer. This paper presents a review and summary of the research results that illustrate the applicability and limitation occurs in the development of biofertilizers.

\section{Research Process}

Several processes were done in this research (Fig. 1). Exploration was the first stage of research activity to isolate endophyte fungi of trees in the peat swamp forest. Endophytic fungi isolated from leaves of the peat swamp forest tree (Fig. 2). Collected leaves were stored in the cooler bag and processed in the laboratory. Leaves cut into small pieces, surface sterilized, and moved into Malt Extract Agar medium. Different morphologies of fungi were tested on a specific Pikovskhaya (PVK) Agar medium, to test its ability in phosphate solubilization (Fig. 3). Twelve endophytic fungi found able to produce clear zones on PVK Agar, which means it has the potential to help phosphate absorption in plants. We identified four species of endophytic fungi which showed the best performance in PVK Agar, i.e. G1.12 (Pestalopsis sp.), M2.6 (Phyllosticta sp.), K1.4 (Endophytic fungi sp.), And P3.10 (P. citrinum).

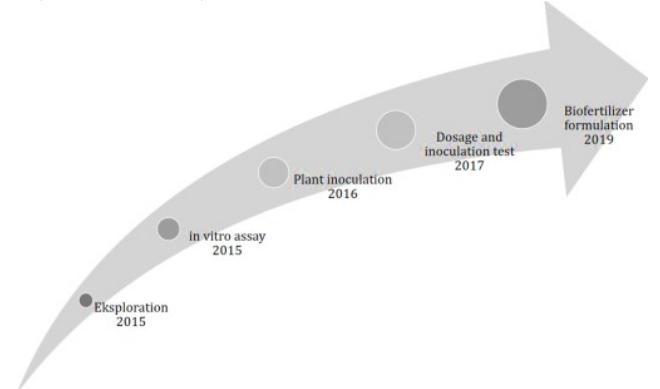

Figure 1. The research process of bioprospection of microbial peat swamp forest. 


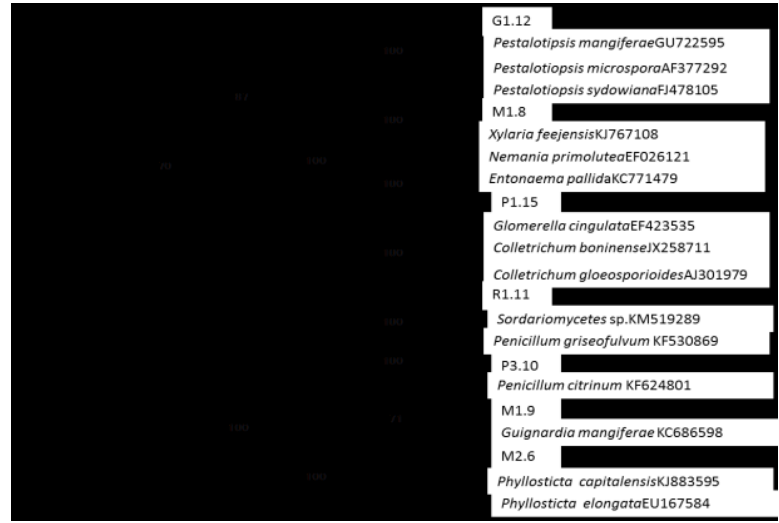

Figure 1. Phylogenetic tree of isolated endophytic fungi of peat-swamp forest in Central Kalimantan.
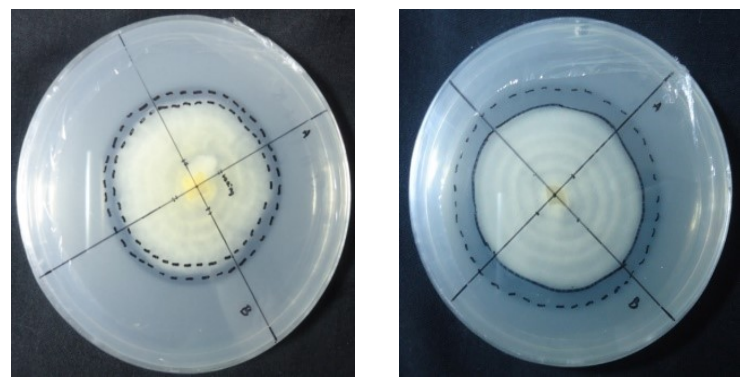

Figure 2. Clear zone in PVK media indicated fungal ability to solubilize phosphate.
Investigating the ability of isolated endophytic fungi acted as a plant growth enhancer in vivo became the main aim of the second year research. Liquid fungi inoculants were inoculated to plant in the greenhouse. After a 12 week observation, endophytic fungi inoculation on Gerunggang (Cratoxylon glaucum) seedlings significantly affected the height but not the plant diameter growth and leaf numbers. To achieve a better understanding of plant responses to endophyte fungi, inoculation tests were done to several plant species at different dosages and application methods. The result of this study showed that variation in dosage and application method, different inoculation frequency, and different plant species did not bring about the different responses to the plant growth. Five months of observation showed there were no differences in plant growth parameters, including height, diameter, leaf numbers, dry weight of plants, soil $\mathrm{P}$ content, and chlorophyll content, between inoculated plants to uninoculated plants (control). Double inoculation which combining endophyte and mycorrhiza was done to obtain a better result. However, the double inoculation method did not significantly affect the growth of nyatoh and sengon in the nursery. The summary of the inoculation test presented in Table 1.

Table 1. Plant response to endophyte inoculation.

\begin{tabular}{|c|c|c|c|c|c|c|}
\hline \multirow{2}{*}{ Plant species } & \multirow{2}{*}{$\begin{array}{l}\text { Research } \\
\text { Treatment }\end{array}$} & \multicolumn{4}{|c|}{ Growth performance } & \multirow[b]{2}{*}{$\mathrm{P}$} \\
\hline & & Height & Diameter & Leaf number & Biomass & \\
\hline \multirow[t]{2}{*}{$\begin{array}{l}\text { Gerunggang } \\
\text { (Cratoxylon glaucum) }\end{array}$} & $\begin{array}{c}\text { Root } \\
\text { inoculation }\end{array}$ & Positive & neutral & neutral & neutral & Negative \\
\hline & $\begin{array}{l}\text { Leaf drop } \\
\text { inoculation }\end{array}$ & Positive & neutral & neutral & neutral & Negative \\
\hline \multirow{6}{*}{$\begin{array}{l}\text { Belangeran } \\
\text { (Shorea belangeran) }\end{array}$} & $5 \mathrm{ml}$, once & neutral & neutral & neutral & neutral & na \\
\hline & $5 \mathrm{ml}$, twice & neutral & neutral & neutral & neutral & na \\
\hline & $3 \mathrm{ml}$, once & neutral & neutral & neutral & neutral & na \\
\hline & $3 \mathrm{ml}$, twice & neutral & neutral & neutral & neutral & na \\
\hline & $1 \mathrm{ml}$, once & neutral & neutral & neutral & neutral & na \\
\hline & $1 \mathrm{ml}$, twice & neutral & neutral & neutral & neutral & na \\
\hline \multirow{6}{*}{$\begin{array}{l}\text { Gerunggang } \\
\text { (Cratoxylon glaucum) }\end{array}$} & $5 \mathrm{ml}$, once & neutral & neutral & neutral & neutral & na \\
\hline & $5 \mathrm{ml}$, twice & neutral & neutral & neutral & neutral & na \\
\hline & $3 \mathrm{ml}$, once & neutral & neutral & neutral & neutral & na \\
\hline & $3 \mathrm{ml}$, twice & neutral & neutral & neutral & neutral & na \\
\hline & $1 \mathrm{ml}$, once & neutral & neutral & neutral & neutral & na \\
\hline & $1 \mathrm{ml}$, twice & neutral & neutral & neutral & neutral & na \\
\hline \multirow{6}{*}{$\begin{array}{l}\text { Ramin } \\
\text { (Gonystylus } \\
\text { bancanus) }\end{array}$} & $5 \mathrm{ml}$, once & neutral & neutral & neutral & neutral & na \\
\hline & $5 \mathrm{ml}$, twice & neutral & neutral & neutral & neutral & na \\
\hline & $3 \mathrm{ml}$, once & neutral & neutral & neutral & neutral & na \\
\hline & $3 \mathrm{ml}$, twice & neutral & neutral & neutral & neutral & na \\
\hline & $1 \mathrm{ml}$, once & neutral & neutral & neutral & neutral & na \\
\hline & $1 \mathrm{ml}$, twice & neutral & neutral & neutral & neutral & na \\
\hline
\end{tabular}

The "formulation" refers to the laboratory or industrial process of unifying the carrier with the microbial strain. "Inoculant" refers to the final product of formulation containing a carrier and microbial agent or consortium of microorganis ms. Formulation beca me the last stage of this multi-year research. In this stage, 
three different carriers. such as sawdust, rice bran, and peat soil, were tested to find out what is the best carrier for P.citrinum. Observation of fungal viability indicated that $P$. citrinum did not growth optimally on these carriers (Hakim et al. unpublished)

\section{Limitation in Endophyte Study and Application}

In general, the three years (2015-2017) of the inoculation study of endophytic fungi on tree seedling showed that the results were ranging from negative to neutral (Table 1). This study contributed to the ambiguity and uncertainty effect of the application of endophyte fungi to plant growth. Moreover, plant responses to endophytic fungi are generally negative [16]. It was also noted that the variability in describing plant response to endophyte inoculation [16]. The study of the endophytic fungi defines that in the plant-fungus interaction, complex environmental parameters affect the interaction [17]. The study revealed that the highest colonization was found in secondary forests compared to the open area. This difference colonization percentage caused by several environmental parameters including microclimate (humidity, water level, soil nutrition, etc.) and habitat condition. Humidity and rainfall have an important role in determining the percentage of endophytic foliar colonization [18].

Several assumptions may clarify the reasons of endophytic fungi to be less optimal on plants. First, inoculated endophytic fungi have difficulty competing with native endophytic fungi in a plant. According to [19] Suryanarayanan (2012), endophytes have properties that are not easy to infect other types of leaves due to the presence of several microbial communities such as native endophytes in these plants, bacteria, etc. Also, the presence of the uncultured fungi that exist inside plant tis sue could be a competitor to endophytic fungi. Second, the presence of secondary metabolites also affects the endophytic inoculation process [19].

To increase the effectiveness and feasibility of endophytic fungi as a plant growth enhancer, endophytic fungi were formulated with a carrier so that it can be used as biological fertilizer. The formulation result during this study showed that the ability of the fungi decreased after 4-week storage. Storage affected the viability of the fungi. For example, Bauveria bassiana fungus was influenced by several factors such as fungal species, carrier properties, storage temperature, and incubation time [20]. A better formulation is needed to make a good biofertilizer. Inputs of technology such as drying method, fluid bed drying method, and nano biofertilizer, can be required to increase the quality of fungal based biofertilizer.

The endophyte study remains many questions as follows: dosage, whether endophyte general or specific fungal type, application method, etc. Despite many references that presented data on the advantage of endophyte fungi, most of the research still conferred data on a laboratory scale. Therefore, research on the endophytic fungi in plants on the application scale still needs to be done and developed.

\section{Conclusion}

1. Penicillium citrinum showed the capability to produce clear zones in Pikovskhaya agar which indicated its ability to solubilize phosphate.

2. After 12 weeks of observation, the result showed that inoculation of endophyte Penicillumcitrinum isolate P3.10 on gerunggang (Cratoxylon glaucum) seedlings performed a significant effect on seedling height.

3. Different plant species, dosage, inoculation methods, formulation caused different effects on tree seedling. As an example: inoculation of endophyte $P$. citrinum isolate P3.10 showed a positive effect on Geronggang height. However, in merapat seedling, there was no significant difference between inoculated and uninoculated seedling

4. Biofertilizer made from Penicillium citrinum in three different carriers (rice barn, sawdust, and peat soil) can be stored only for a maximum of 28 days that indicated the difficulties of biofertilizer formulation, handling, and storage.

\section{References}

1. Bayman P., In K. CP and D. IS (Eds.), Environmental and Microbial Relationships, 2nd Edition, 213-227, Berlin Heidelberg: SpringerVerlag, (2007)

2. M. S, Khan, , A. Zaidi, , M. Ahemad, M.Oves, and P. A Wani, Arch. Agron. and Soil Sci., 56, 1, 73-98, (2010)

3. Q. Liu, A. J. Parsons, H.Xue, K.Fraser, G. D. Ryan, J.A. Newman, \& S. Ras mussen, Funct. Ecol., 25, 910-920, (2011)

4. A. F. Maulana, M. Turjaman, and Y. Hashimoto, $J$. Exp. Agric. Int., 18(5), 1-11. (2017)

5. J. Rudgers, T. E.Miller, S. M. Zielger, and K. D. Craven, Ecol., 93, 3, 565-574, (2012).

6. V. Novas, L. J. M. Iannone, A. M. Godeas, , and D. Cabral, Mycol. Prog., 8 (1), 75-81, (2009).

7. A. H. Fouda, S. E. Hassan, A. M. Eid, and E. E. Ewais, Annals Agric. Sci., 60, 1, 95-104 (2015)

8. B. F. Lau, N. Abdullah, N. A minudin, H. Boon, and P. J. Jean, Ethnopharmacol., 169, 441-458, (2015)

9. S. S. N. Maharachchikumbura, G. Liang-Dong, E. Chukeatirote, A. H. Bahkali, and K. D. Hyde, Fungal Divers., 50, 167-187. (2011).

10. T. S. Suryanarayanan, V. Gopalan, R. U. Shaanker, G. Ravikanth, and A. Sengupta, In J. de Azedevo \& M. Quecine (Eds.), Diversity and Benefits of Microorganism from the Tropics, 342-365, Springer International Medicine, (2017) 
11. S. Kumar, N. Kaushik, R. Edrada-Ebel, R. Ebel, and P. Proksch, In A. Ciancio \& K. Mukerji (Eds.), Integrated Management of Diseases Caused by Fungi, Phytoplasma and Bacteria, 365-387), Dordrecht, Springer Science Business Media, (2008)

12. E. Li, L. Guo, C. Academy, H. Zhang, and Y. C. Beijing, Bioorg. \& Med. Chem., 16, 7894-7899, (2008)

13. S. S. Hakim, S. W. Budi, and M. J. Turjaman, Man. Hutan Trop., 21, 138-146, (2015).

14. S. A. Khan, M. Hamayun, H. Yoon, H-Y. Kim, S.-J. Suh, S-K. Hwang, I-J. Kim, Y-S. Lee, U-H. Yoon, W.S. Choo, B-M. Kong, and J.-G.Lee, $B M C$ Microbiol., 8,231 , (2008)

15. L. Gasoni, and B. S. D. E.Gurfinke1, Mycol. Res., 101(7): 867-870, (1997)

16. M. S.Mayerhofer, G. Kernaghan, and K. A. Harper, Mycorr., 23(2):119-128, (2012)

17. S.S. Hakim, T. W. Yuwati, and S.J.Nurulita, Wetland Env. Man., 5(1): 10-17, (2017)

18. K. Saikkonen, Fungal Biol. Rev., 21(2-3): 67-74, (2007)

19. T. S. Suryanarayanan, Fungal Diversity, 54, 19-30, (2012)

20. P.K Sahu, and G. Bramaprakash, In D. P. Singh, R. Prabha, and H. B. Singh (Eds.), Microbial Inoculants in Sustainable Agricultural Productivity, 179-198, Springer Indiam New Delhi, (2016). 